\title{
A Comparative Evaluation of Antibacterial Potential of Some Plants Used in Indian Traditional Medicine for the Treatment of Microbial Infections
}

\author{
Rabi Ranjan Chattopadhyay*, Subir Kumar Bhattacharyya, Chiranjib Medda, Sunanda \\ Chanda and Anwesa Bag \\ Agricultural and Ecological Research Unit; Indian Statistical Institute; Barrackpore Trunk Road, Kolkata - 700 \\ 108, India
}

\begin{abstract}
A comparative in vitro antibacterial potential of extracts (aqueous and ethanol) of five important medicinal plants (Aegle marmelos, Azadirachta indica, Terminalia chebula, Mangifera indica and Ocimum sanctum) were investigated using microbial growth inhibition assays against the common human pathogenic bacteria (Staphylococcus aureus, Pseudomonas aeruginosa and Escherichia coli) of clinical origin. All the plant materials showed varying degrees of strain specific inhibitory action and ethanol extract of the plant materials showed higher antibacterial activity than their aqueous counterparts. Besides, T. chebula and A. marmelos had the strongest antibacterial activity out of which, T. chebula possessed a wider spectrum and a superior antibacterial potential over the others. The bioactive compounds of T. chebula might have potential as therapeutic agents for the treatment of common bacterial infections.
\end{abstract}

Key words: Pathogenic bacteria, Medicinal plants, Antibacterial potential, Comparative study.

\section{INTRODUCTION}

In recent years, multiple drug resistance has developed due to indiscriminate use of existing antimicrobial drugs in the treatment of infectious diseases (Service 1995). This problem demands that a renewed effort to seek the antibacterial agents effective against the pathogenic microorganisms resistant to current antibiotics (Soulsby 2005). Besides, though synthetic antibiotics are strong medicines and save lives, they cause more harm than good when they are not used in right way (Neu 1992). Therefore, there is also a need to develop alternative antimicrobial drugs for the treatment of infectious diseases from other sources. One of the possible strategies towards this objective is the rational localization of bioactive phytochemicals (Cordell 2000). Plants are rich in a wide variety of secondary metabolites such as tannins, terpenoids, alkaloids and flavonoids which in vitro show the antimicrobial properties and could serve as an alternative, effective, cheap and safe antibacterial for the treatment of microbial infections (Cowan 1999). Tannin, which is a phenolic compound and is soluble in water, alcohol and acetone, gives precipitates with proteins. The antibacterial activity of tannin is well documented. The growth of many fungi, yeast, bacteria and viruses can be inhibited by the tannin. Tannin serves as natural

\footnotetext{
* Author for correspondence: rabi@isical.ac.in
} 
defense mechanisms against the microbial infections (Chung et al. 1988).

Some plants such as Ocimum sanctum Linn. (Labiatae; Tulsi), Aegle marmelos correa (Rutaceae, Bael), Azadirachta indica A. Juss. (Meliaceae; Neem), Terminalia chebula (Combretaceae; Harad or Haritaki) and Mangifera indica (Anacardiaceae; Mango) have been commonly used for the treatment of microbial infections (Chopra et al. 1956; Kirtikar and Basu 1933; Nadkarni 1954). In the present investigation, an attempt was made to elucidate the possible antibacterial activity of these plant materials against the common pathogenic bacteria $S$. aureus, $P$. aeruginosa and $E$. coli of clinical origin as well as standard type strains and also to compare their antibacterial potential against the test strains with respect to standard antimicrobial drug, gentamicin.

\section{MATERIALS AND METHODS}

\section{Collection, extraction and formulation of plant materials:}

Fresh matured plant materials [O. sanctum (leaf), A. indica (leaf), A. marmelos (leaf), T. chebula (fruit) and $M$. indica (leaf)] were collected from different places of West Bengal and were identified and authenticated by a botanist. Airdried powder of leaves/fruits of each plant was extracted with water and ethanol for $24 \mathrm{~h}$ in Soxhlet apparatus. The solvents were removed in rotary evaporator and the crude extracts were dried at room temperature in a steady air-current. The dried extracts of the plant materials were then stored in air-tight jars at $4^{\circ} \mathrm{C}$ for microbial analysis. The formulation of the extracts were made by dissolving the ethanolic extract of each plant material in 5\% dimethylsulphoxide (DMSO) and aqueous extract in distilled water to a final concentration of $100 \mathrm{mg} / \mathrm{ml}$.

\section{Microorganisms}

Both, the clinical isolates and reference standard strains were used in this study. Clinical isolates of Staphylococcus aureus (1.c.i.), Pseudomonas aeruginosa (1.c.i.) and Escherichia coli (1.c.i.) were collected from the Department of Bacteriology and Serology, Calcutta School of Tropical Medicine, Kolkata and type strains of Staphylococcus aureus (ATCC 6538P), Pseudomonas aeruginosa (ATCC 9027) and
Escherichia coli (ATCC 8739) were procured from the National Collection of Industrial Microorganisms, Pune, India and were maintained in nutrient agar slants.

\section{Susceptibility test}

The tested bacterial strains were inoculated into Mueller Hinton Broth (Oxoid) medium and incubated for $3-6 \mathrm{~h}$ at $35^{\circ} \mathrm{C}$ in a shaker water bath until the culture attained a turbidity of 0.5 McFarland unit. The final inoculum size was adjusted to $5 \times 10^{5} \mathrm{cfu} / \mathrm{ml}$ (NCCLS 1993). Susceptibility tests were performed by a modified agar-well diffusion method [well technique in double layer (Okunji et al. 1990; Okeke et al. 2001)]. A $1.0 \mathrm{ml}$ volume of the standard suspension of each test bacterial strain was spread evenly on Mueller Hinton Agar using a sterile glass rod spreader and the plates were allowed to dry at room temperature. Subsequently, 6-mm diameter wells were bored in the agar and a $100 \mu 1$ volume of $100 \mathrm{mg} / \mathrm{ml}$ of each of the reconstituted extract (both aqueous and ethanol) were transferred into the wells. After holding the plates at room temperature for $2 \mathrm{~h}$, they were incubated at $37^{\circ} \mathrm{C}$ for $24 \mathrm{~h}$. Inhibition zone diameter (IZD) was measured to the nearest millimeter $(\mathrm{mm})$. Gentamicin (Nicholas, India) $(8 \mu \mathrm{g} / \mathrm{ml})$ was used as the experimental positive control and 5\% DMSO as negative control. The tests were performed in triplicate for each bacterial strain evaluated and the final results were expressed as arithmetic average.

Only the extracts showing strong inhibitory zone diameter (IZD $=12 \mathrm{~mm}$ or more) and wider spectrum of antibacterial activity (Baur et al, 1966) were assessed further for their minimal inhibitory concentration (MIC), minimal bactericidal concentration (MBC) and total activity determination against the clinical isolates. Since, the inhibitory action of both $T$. chebula and $A$. marmelos against the type strains and clinical isolates were more or less the same as observed from their IZD values, MIC, MBC and total activity values of the extracts were tested against the clinical isolates only.

\footnotetext{
Determination of minimal inhibitory concentration (MIC)

Minimal inhibitory concentration values of ethanol extract of $T$. chebula and A. marmelos plant materials against each of the bacterial test strains
} 
were determined by the macrobroth dilution assay method (NCCLS 1993). Two-fold serial dilution of the ethanol extracts of $T$. chebula and $A$. marmelos $(0.1-100 \mathrm{mg} / \mathrm{ml})$ were prepared in tubes with Mueller Hinton Broth as diluent. Duplicate tubes of each dilution were seeded with test organisms to the standards concentration $\left(5 \times 10^{5}\right.$ $\mathrm{cfu} / \mathrm{ml})$. Two-fold serial dilution of gentamicin (Nicholas, India) $(0.125-512 \mu \mathrm{g} / \mathrm{ml})$ was used as the experimental positive control. The tubes were incubated at $37^{\circ} \mathrm{C}$ for $24 \mathrm{~h}$. The least concentration of the extract showing no visible growth was taken as the MIC.

\section{Determination of minimal bactericidal concentration (MBC)}

The minimal bactericidal concentration (MBC) was determined by aspirating $0.1 \mathrm{ml}$ of culture medium from each tube (in the macrobroth MIC assay) showing no apparent growth and subculturing it on the fresh MHA. The MHA plates were incubated at $37^{\circ} \mathrm{C}$ for $24 \mathrm{~h}$. The $\mathrm{MBC}$ was read as the least concentration showing no visible growth on MHA sub-culture. From the obtained values of $\mathrm{MIC}$ and $\mathrm{MBC}$, the $\mathrm{MIC}_{\text {index }}$ (MBC/MIC) values were computed for T. chebula and $A$. marmelos against each strain evaluated.

\section{Determination of total activity}

The total activity (Ta) of the ethanol extract of $T$. chebula and A. marmelos were measured from the per gram extracted material and MIC values against each of the test strain using the following mathematical equation to compare the antibacterial potency of $A$. marmelos and $T$. chebula extracts quantitatively (Eloff 2004).

$$
\mathrm{Ta}(\mathrm{ml})=
$$

Amount extracted from $1 \mathrm{~g}(\mathrm{mg})$

$\mathrm{MIC}\left(\mathrm{mg} \mathrm{ml}^{-1}\right)$
The units were adjusted to $\mathrm{ml}$ and indicated the degree to which the active extracts in one gram of plant material could be diluted and still inhibited the growth of the test organisms (Eloff 2004).

\section{RESULTS}

Table 1 showed that both, the aqueous and ethanol extracts of $A$. indica had strong (IZD $=18 \mathrm{~mm}$ and $20 \mathrm{~mm}$ ) inhibitory action against $S$. aureus but failed to show any promising (IZD $=8 \mathrm{~mm}$ or more) inhibitory effect against the Gram-negative bacteria $P$. aeruginosa and E. coli. Ethanol extract of $O$. sanctum and $M$. indica showed intermediate $(\mathrm{IZD}=9 \mathrm{~mm}-11 \mathrm{~mm})$ inhibitory action against all the test strains. But their aqueous extracts failed to show any promising inhibitory effect (IZD $=8 \mathrm{~mm}$ or more) against all the strains evaluated. The aqueous extracts of $T$. chebula and A. marmelos showed intermediate (IZD $=8 \mathrm{~mm}-10 \mathrm{~mm}$ ) but their ethanol extracts showed strong $($ IZD $=15$ $\mathrm{mm}$ to $23 \mathrm{~mm}$ ) inhibitory action against all the strains evaluated. The percentage of inhibition of the plant extracts against the test strains with respect to gentamicin ranged from 19 to $100 \%$.

The inhibitory action of the plant extracts against the standard type strains were more or less the same as observed against the clinical isolates.

Table 2 showed that the MIC values for $T$. chebula and A. marmelos against the test strains ranged from 1.56 to $3.12 \mathrm{mg} / \mathrm{ml}$ and 3.12 to $6.25 \mathrm{mg} / \mathrm{ml}$, respectively. The MBC values for $T$. chebula ranged from 1.56 to $6.25 \mathrm{mg} / \mathrm{ml}$ and for $A$. marmelos from 12.50 to $50.0 \mathrm{mg} / \mathrm{ml}$. $\mathrm{MIC}_{\text {index }}$ values for $T$. chebula were 1 to 2 and for $A$. marmelos 4 to 8 . The total activity values for $T$. chebula against the test strains ranged from 154.7 to $309.4 \mathrm{ml}$ and for A. marmelos from 107.5 to $215.0 \mathrm{ml}$. The MIC, MBC, $\mathrm{MIC}_{\text {index }}$ for gentamicin against the test strains were $2-8,4-32$, and $2-4$ $\mu \mathrm{g} / \mathrm{ml}$, respectively. 
Table 1 - Antibacterial effect of extracts of medicinal plants against the pathogenic bacteria $S$. aureus, P. aeruginosa and E. coli as indicated by inhibitory zone diameter

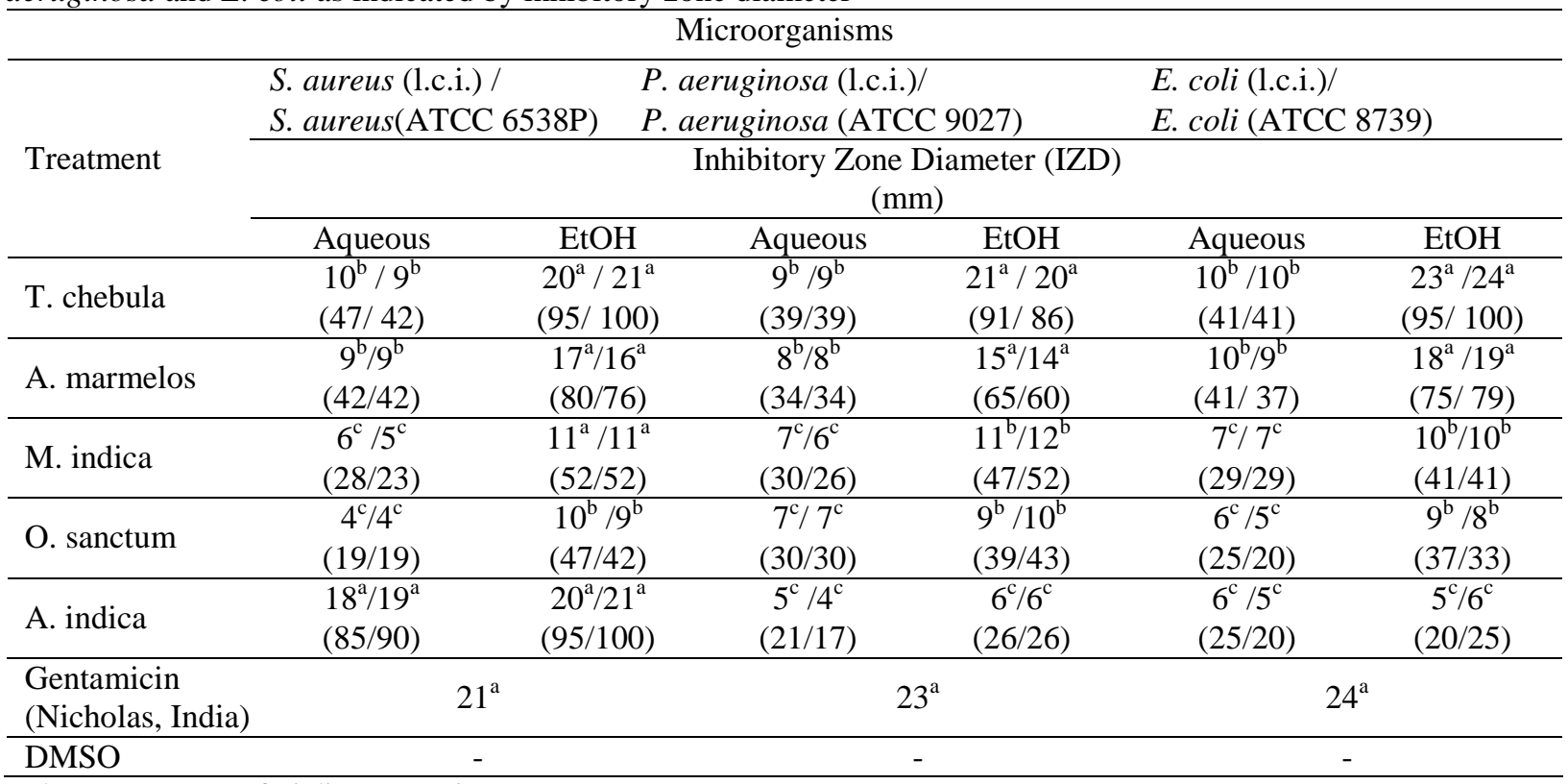

Values are average of triplicate experiments.

(-) : Absence of inhibition.

${ }^{\mathrm{a}}$ Sensitive ; ${ }^{\mathrm{b}}$ Intermediate ; ${ }^{\mathrm{c}}$ Resistant

Values in parenthesis indicate per cent of inhibition with respect to reference standard antibiotic Gentamicin.

Table 2 - The minimal inhibitory concentration (MIC), minimal bactericidal concentration (MBC), $\mathrm{MIC}_{\text {index }}$ and total activity values of ethanolic extracts of T. chebula and A. marmelos against the test pathogens

\begin{tabular}{llcccc}
\hline Treatment & Microorganisms & $\begin{array}{c}\mathrm{MIC} \\
(\mathrm{mg} / \mathrm{ml})\end{array}$ & $\begin{array}{c}\mathrm{MBC} \\
(\mathrm{mg} / \mathrm{ml})\end{array}$ & $\mathrm{MIC}_{\text {index }}$ & $\begin{array}{c}\text { Total Activity } \\
(\mathrm{ml})\end{array}$ \\
\hline \multirow{3}{*}{ T. chebula } & S. aureus & 1.56 & 1.56 & 1.0 & $482.6 / 1.56=309.4$ \\
& P. aeruginosa & 3.12 & 6.25 & 2.0 & $482.6 / 3.12=154.7$ \\
& E. coli & 3.12 & 6.25 & 2.0 & $482.6 / 3.12=154.7$ \\
\hline \multirow{2}{*}{ A. marmelos } & S. aureus & 3.12 & 12.50 & 4.0 & $670.8 / 3.12=215.0$ \\
& P. aeruginosa & 6.25 & 50.00 & 8.0 & $670.8 / 6.25=107.5$ \\
& E. coli & 6.25 & 50.00 & 8.0 & $670.8 / 6.25=107.5$ \\
\hline \multirow{2}{*}{ Gentamicin } & S. aureus & $2.00^{*}$ & $4.00^{*}$ & 2.0 & - \\
(Nicholas, India) & P. aeruginosa & $8.00^{*}$ & $32.00^{*}$ & 4.0 & - \\
& E. coli & $8.00^{*}$ & $32.00^{*}$ & 4.0 & - \\
\hline
\end{tabular}

$* \mu \mathrm{g} / \mathrm{ml}$

\section{DISCUSSION}

S. aureus owes its clinical significance due to the fact that it causes a variety of suppurative (pusforming) infections and toxinoses in the humans. It causes superficial skin lesions such as boils, styes and furunnculosis; more serious infections such as pneumonia, mastitis, phlebitis, meningitis and urinary tract infections. S. aureus is a major cause of hospital acquired (nosocomial) infection of the surgical wounds and infections associated with indwelling medical devices. S. aureus causes food poisoning and toxic shock syndrome by the release of superantigens into the blood stream (Michael et al. 1999). $P$. aeruginosa owes its clinical significance to the fact that it is an aetiology of a good number of infections such as septic burns and wounds, conjunctivitis, endocarditis, meningitis, and urinary tract infections. Notably, it serves as a reference species in susceptibility 
testing on account of its notorious resistance to most antimicrobial compounds (Ho et al. 1998). Similarly, E. coli, though normally a gut commensal, has attracted the clinical significance owing to the recognition of several strains of diarrhoeagenic $E$. coli with distinct virulent factors and also an important organism in urinary tract infections (UTIs) (Johnson 1991).

The present study revealed that all the plant materials possessed strain specific antibacterial activity and ethanol was the suitable solvent for the extraction of bioactive plant materials. According to Baur et al. (1966) classification, the bactericidal activity is classified into (i) resistant: if the zone of inhibition is less than $8 \mathrm{~mm}$, (ii) intermediate: if it is 8 to $11 \mathrm{~mm}$, and (iii) sensitive: if the zone of inhibition is $12 \mathrm{~mm}$ or more. On the basis of this classification, the present findings revealed that all the test strains were sensitive to the ethanol extract of T. chebula and A. marmelos, Intermediate action was observed for $M$. indica and $O$. sanctum and both aqueous and ethanol extracts of $A$. indica were sensitive only against Gram-positive $S$. aureus. When the potency of both, the aqueous and ethanol extract of each plant material was compared with gentamicin, a reference standard antibiotic, the ethanol extract of both $T$. chebula and A. marmelos showed strong wider spectrum of antibacterial activity (60-100\%) against all the test strains with respect to gentamicin.

Though the crude plant preparations have generally been reported to exhibit the lower antimicrobial activity than the pure antibiotic substances, such as gentamicin (Ebi and Ofoefule 1997; Ibrahim et al. 1997), high bactericidal activity, low $\mathrm{MIC}_{\text {index }}(1.0-2.0)$, high total activity and wider spectrum of antibacterial property observed for the ethanol extract of $T$. chebula against all the test strains in this study indicated its wider spectrum superior antibacterial potential when compared with other plant materials used.

Chemical analysis revealed that $T$. chebula contained 24-32\% tannin (Chung et al. 1988). The chief constituent of this tannin was chebulagic acid, chebulinic acid, corilagin and gallic acid. It had 18 amino acids. Resin and purgative principle of anthroquinone and sennoside nature was also present (http://www.holistic-herbal.com/terminalia -chebula -1.html). Since both, the ethanolic and aqueous extract of $T$. chebula possessed antibacterial activity. It was presumed that the antibacterial activity of $T$. chebula could be due to the presence of high content of tannins in it.

Thus, the present study has shown that $T$. chebula has the wide spectrum antibacterial activity and could be a more potent antibacterial agent among the plant materials used. The high content of tannin present in it might be responsible for its antibacterial activity. This reinforces the importance of ethnomedical approach as a potential source of bioactive substances for the treatment of infectious diseases caused by these pathogenic microorganisms.

\section{ACKNOWLEDGEMENT}

Authors wish to acknowledge Prof. N.K. Pal, Head, Department of Bacteriology and Serology, Calcutta School of Tropical Medicine, Kolkata and Prof. M. Ghose, Head, Agricultural and Ecological Research Unit, Indian Statistical Institute, Kolkata for their co-operation and help during this work.

\section{REFERENCES}

Baur, A.W.; Kirby, W.M.; Sherris, J.C. and Turck, M. (1966), Antibiotic susceptibility testing by a standard single disc method. Am J Clin Pathol, 45, 493-496.

Chopra, R.N.; Nayar, S.L. and Chopra, I.C.(1956), Glossary of Indian Medicinal Plants (CSIR, New Delhi).

Chung, K.T.; Wong, T.Y.; Wei, C.I.; Huang, Y.W. and Lin, Y. (1988), Tannins and human health: a review. Crit. Rev. Food. Sci. Nutr., 38(6), 421-464.

Cordell, G.A. (2000), Bioderversity and Drug discovery: a symbiotic relationship. Phytochemistry, 55, 463-480.

Cowan, M.M. (1999), Plant products as antimicrobial agents. Clin Microbiol Rev. 12(4), 564-582.

Ebi, G.C. and Ofoefule, S.I. (1997), Investigations into folkloric antimicrobial Activities of Landolphia owerrience. Phytother Res. 11, 149-151.

Eloff, J.N. (2004), Quantifying the bioactivity of plant extracts during screening and bioassay-guided fractionation. Phytomedicine, 11, 370-370.

Ho, P., Chan; K., Mary; S.M., Lam; W., Ho, C.;

Yuen, K. and Tsang, W. (1998), The effect of Pseudomonas aeruginosa infection on clinical parameters in steady-state bronchiectasis. Chest. 114, 1594-1598. 
Ibrahim, M.B.; Owonubi, M.O. and Onaolapo, J.A. (1997), Antimicrobial effects of extracts of leaf, stem and root bark of Anogiessus bicarpus on Staphylococcus aureus NCTC 8198, Escherichia coli NCTC 10418 and Proteus vulgaris NCTC 4636. J. Pharm Res Develop. 2, 20-26.

Johnson, J. R. (1991), Virulence factors in Escherichia coli urinary tract infections. Clin. Microbiol. Rev. 4(1), 80-128.

Kirtikar, K.R. and Basu, B.D. (1933), Indian Medicinal Plants (LM Basu, Allahabad).

Michael, B.; Edmond, S. E.; Wallace, D. K.; McClish, M. A.; Pfaller, R. N.; Jones, R. and Wenzel, P. (1999), Nosocomial blood stream infections in United States hospitals: A three year analysis. Clin. Infect. Dis. 29, 239-244.

Nadkarni, A.K. (1954), In: Dr KM Nadkarni's Indian Materia Medica, (Popular Prakason, Bombay). National Committee for Clinical Laboratory Standards(1993), Methods for dilution in antimicrobial susceptibility test. Approved standards M2-M5, National Committee for Clinical Laboratory Standards, Villanova, PA.
Neu, H.C. (1992), The crisis in antibiotic resistance. Sciene, 257, 1050-1055.

Okeke, M.; Iroegbu, C.U.; Eze, E.N.; Okoloi, A.S.and Esimone, C.O. (2001), Evaluation of extracts of root of Landonphin owerrience for antibacterial activity. J. Ethnopharmacol. 78(2-3), 119-127.

Okunji, C.O.; Okeke, C.N.; Gugnani, H.C.and Iwu, M.M. (1990), An antifungal saponin from fruit pulp of Dracaena manni. Int J Crude drug Res. 28(3), 193-199.

Service, R.F. (1995), Antibiotics that resist resistance. Science, 270, 724-727.

Soulsby, L. (2005), Resistance to antimicrobials to humans and animals. Brit J Med. 331, 1219-1220.

Terminalia chebula/Ayurvedic herbal Rejuvenating Herb (http://www.holistic- herbalist.com/terminalia_ chebula_1.html) 